\title{
IN VITRO TESTING OF TIGECYCLINE AMONG THE CLINICALLY SIGNIFICANT BACTERIAL ISOLATES OBTAINED FROM BLOOD STREAM INFECTION IN A TERTIARY CARE CENTRE OF EASTERN NEPAL
}

\author{
Abhilasha Sharma1, Narayan Raj Bhattarai², Basudha Khanal ${ }^{3}$
}

${ }^{1}$ Assistant Professor, Department of Microbiology, B. P. Koirala Institute of Health Sciences, Dharan, Nepal.

${ }^{2}$ Additional Professor, Department of Microbiology, B. P. Koirala Institute of Health Sciences, Dharan, Nepal.

${ }^{3}$ Professor and HOD, Department of Microbiology, B. P. Koirala Institute of Health Sciences, Dharan, Nepal.

\section{ABSTRACT}

\section{BACKGROUND}

Multidrug resistant organisms like methicillin resistant Staphylococcus aureus (MRSA), vancomycin resistant enterococci (VRE) and extended spectrum beta lactamase (ESBL) producing organisms are being encountered as the causative agents of blood stream infection. Tigecycline has been designed to overcome resistant mechanisms of these agents. Therefore, this study was carried out to identify Methicillin resistant Staphylococcus aureus, vancomycin resistant enterococci and extended spectrum beta lactamase producing organisms in blood culture isolates at Microbiology Laboratory and to determine the antimicrobial susceptibility of tigecycline against them.

\section{MATERIALS AND METHODS}

A descriptive study was carried out in Microbiology Laboratory, BP Koirala Institute of Health Sciences, Dharan, Nepal. Altogether 125 Staphylococcus aureus, 60 Enterococci and 150 Gram Negative Bacteria (GNB) were obtained during 1 year period (July 2011 June 2012). Laboratory detection of MRSA, VRE and ESBL producers and antimicrobial testing of tigecycline were done following standard protocol.

\section{RESULTS}

Overall analysis determined 24\% were MRSA, 3\% VRE and 47\% of ESBL producing bacterial isolates respectively. Tigecycline showed $100 \%$ sensitivity among MRSA and VRE, whereas $12.6 \%$ of ESBL producing GNB were resistant to tigecycline.

\section{CONCLUSION}

MRSA, VRE and ESBL producing bacteria are identified in blood culture isolates at BPKIHS. Tigecycline demonstrated the excellent antimicrobial activity against MRSA and VRE, but the decreased performance on gram negative isolates including ESBL producers which is indeed another alarming issue for further use of new drug.

\section{KEYWORDS}

Tigecycline, Methicillin Resistant Staphylococcus Aureus, Vancomycin Resistant Enterococci.

HOW TO CITE THIS ARTICLE: Sharma A, Bhattarai NR, Khanal B. In vitro testing of tigecycline among the clinically significant bacterial isolates obtained from blood stream infection in a tertiary care centre of Eastern Nepal. J. Evolution Med. Dent. Sci. 2016;5(88):6584-6587, DOI: 10.14260/Jemds/2016/1488

\section{BACKGROUND}

Blood Stream Infections (BSI) are responsible for considerable morbidity and mortality worldwide. ${ }^{1}$ Diverse spectrum of organisms are encountered as causative agents of blood stream infection. In the recent years, resistant organisms are frequently encountered as aetiological agents of BSI. Methicillin resistant Staphylococcus aureus (MRSA) has now been recognised as a major hospital pathogen in addition to the exponential spread of Vancomycin Resistant Enterococci (VRE) and Extended Spectrum Beta Lactamase (ESBL) producers. ${ }^{2}$ All these emerging threats inactivate the most common antibiotics like penicillins, cephalosporins, fluoroquinolones, aminoglycosides and tetracyclines.3,4

Financial or Other, Competing Interest: None.

Submission 28-09-2016, Peer Review 22-10-2016,

Acceptance 28-10-2016, Published 03-11-2016.

Corresponding Author:

Abhilasha Sharma,

Assistant Professor,

Department of Microbiology,

B. P. Koirala Institute of Health Sciences,

Dharan, Nepal.

E-mail:abhilasha2014.as@gmail.com

DOI: $10.14260 /$ jemds $/ 2016 / 1488$

(c) $(1)$
Tigecycline seems to be promising in the treatment of infections caused by multidrug resistant organisms. It is a bacteriostatic agent and has a potent in-vitro activity against gram positive and gram negative organisms. It has been designed to overcome many existing mechanisms of resistance among bacteria and provides broad antimicrobial coverage against MRSA, VRE and ESBL producers too. ${ }^{5}$ Therefore, our study was undertaken with an aim to determine the tigecycline activity on the clinical isolates obtained from routine blood culture in a tertiary care centre of Eastern Nepal.

\section{MATERIALS AND METHODS}

Ethical clearance was obtained from Institutional Review Committee of B. P. Koirala Institute of Health Sciences, Dharan, Nepal.

\section{Study Site and Sampling}

A descriptive study was carried out in the Department of Microbiology, B. P. Koirala Institute of Health Sciences, Dharan, which is a tertiary care Health Sciences University located in Eastern part of Nepal. The sampling was done from July 2011 to June 2012. Out of total 6262 blood culture samples submitted, altogether 125 isolates of S. aureus, 60 
Enterococci and 150 gram negative bacilli were tested for in vitro activity of tigecycline.

\section{Microbiological Testing}

Isolation and identification of isolates was done following standard microbiological protocol with the help of colony morphology, gram stain and conventional biochemical tests. 6,7

Antimicrobial susceptibility test was performed by standard disk diffusion method recommended by Clinical Laboratory Standard Institute (CLSI) guidelines for all antibiotics disks [Hi Media] except tigecycline for which FDA guidelines were taken.8,9

\section{Detection of MRSA}

Was done using Oxacillin disk diffusion test following standard protocol. A colony of S. aureus isolate was prepared to a 0.5 McFarland standard and plated on Mueller Hinton agar containing $4 \% \mathrm{NaCl}$. An oxacillin disk of $1 \mu \mathrm{g}$ was placed on the surface and incubated at $35^{\circ} \mathrm{C}$ for 24 hours. The zone of inhibition was read with transmitted light. Zone diameter $\geq$ $13 \mathrm{~mm}$ was considered as susceptible, whereas zone of inhibition $\leq 10 \mathrm{~mm}$ was considered resistant. Zone size of 11 - $12 \mathrm{~mm}$ was considered intermediate. ATCC $25923 \mathrm{~S}$. aureus was used as control.10

\section{Detection of VRE}

Was done as per standard protocol using vancomycin screening agar. Isolated enterococci inoculum was taken and inoculated onto Mueller Hinton agar with $5 \%$ of sheep blood containing $6 \mu \mathrm{g} / \mathrm{mL}$ of vancomycin. It was then incubated for 24 hours at $35^{\circ} \mathrm{C}$ and next day observed for any growth. Any growth in the media was taken as indicative of vancomycin resistance. Enterococcus faecalis ATCC 29212 was used in each plate as control. ${ }^{8}$

\section{Detection of ESBL}

All the gram negative bacilli were tested for ESBL production by a double disk diffusion synergy test method recommended by CLSI. An enhanced zone of inhibition with a diffusion of $\geq$ to $5 \mathrm{~mm}$ around the ceftazidime and clavulanic acid disk as compared to the ceftazidime disk alone was interpreted as the presence of ESBL. Klebsiella pneumoniae ATCC 700603 as positive control and Escherichia coli ATCC 25922 as negative control were inoculated in separate culture plate along with test organisms. ${ }^{11}$

\section{Determination of MIC}

MIC of tigecycline was determined by agar dilution technique as per CLSI guideline. The control strain ATCC 25923 S. aureus, ATCC 29212 E. faecalis and ATCC 25922 Esch. coli were used.12,13

\section{RESULTS}

One hundred and twenty five S. aureus isolates, 60 Enterococci and 150 gram negative isolates were evaluated. Out of 335 isolates, 302 (90\%) were obtained from patients admitted in the wards and rest from the patients attending the outpatient department. About 57\% were obtained from the male patients and remaining from the female patients. Most of the gram positive isolates belonged to the age group of $0-10$ years $(52 \%$ and $66.6 \%$ for S. aureus and Enterococci respectively), followed by 21 - 30 years. Most of the gram negative isolates (100) obtained from the patients also belonged to the age group below 10 years (68.6\%).

\section{Antimicrobial Susceptibility Testing}

Antimicrobial susceptibility testing by Kirby-Bauer disk diffusion method of S. aureus demonstrated the resistance of all the 125 isolates to penicillin whereas all were sensitive to vancomycin, linezolid and tigecycline. Additionally, susceptibility to gentamicin, ciprofloxacin, cefotaxime, azithromycin and cotrimoxazole was noted in 94.4\%, 81.6\%, $60.8 \%, 60.8 \%$ and $59.2 \%$ of $\mathrm{S}$. aureus respectively. Antimicrobial susceptibility pattern of 60 enterococcal isolates showed that no isolates were found to be resistant to linezolid and tigecycline, whereas $97 \%, 55 \%$ and $50 \%$ of isolates were susceptible to vancomycin, gentamicin and ciprofloxacin respectively. Among 150 gram negative isolates resistance to ampicillin, cefotaxime, ceftriaxone and gentamicin was observed in $97.3 \%, 86 \%, 82 \%$ and $53 \%$ respectively and sensitivity to imipenem and tigecycline was seen in $98.6 \%$ and $82.6 \%$ respectively.

\section{Detection of MRSA, VRE and ESBL}

Out of 125 S. aureus isolates, $24 \%$ were found to be MRSA. Out of 60 enterococcal isolates 3.3\% isolates were detected to be vancomycin resistant. And among 150 gram negative isolates, $47.3 \%$ were found to be ESBL producers. Among those 71 ESBL producers, K. pneumoniae and Esch. coli were the most frequent.

\section{MIC of Tigecycline}

Among the $125 \mathrm{~S}$. aureus isolates, both MSSA and MRSA were susceptible to tigecycline as inhibition of growth occurred at $\leq 0.5 \mathrm{mg} / \mathrm{L}$ of tigecycline as shown in Figure 1. Among the 60 Enterococci, all the isolates including VRE were susceptible to tigecycline as MIC was $\leq 0.25 \mathrm{mg} / \mathrm{L}$ as shown in Figure 2. MIC of tigecycline for gram negative isolates showed that out of 150 gram negative isolates, $82.6 \%$ were susceptible to tigecycline at MIC $\leq 2 \mathrm{mg} / \mathrm{L}$ and $17.3 \%$ showed resistance as those were inhibited at $\geq 8 \mathrm{mg} / \mathrm{L}$, which was similar to the disk diffusion test for tigecycline. Among 26 tigecycline resistant isolates Acinetobacter anitratus were 16, Enterobacter species 3, Pseudomonas aeruginosa 2, Proteus mirabilis 2 and Esch. coli 1, which showed MIC of tigecycline $\geq 8 \mathrm{mg} / \mathrm{L}$ as depicted in Table 1 . Comparing the susceptibility of tigecycline among ESBL producers and non-ESBL producers, it was found that among 71 ESBL producers and 79 non-ESBL producers resistance to tigecycline was observed in $12.6 \%$ and $22.7 \%$ respectively. So irrespective of production of ESBL, resistance to tigecycline was observed in gram negative bacilli.

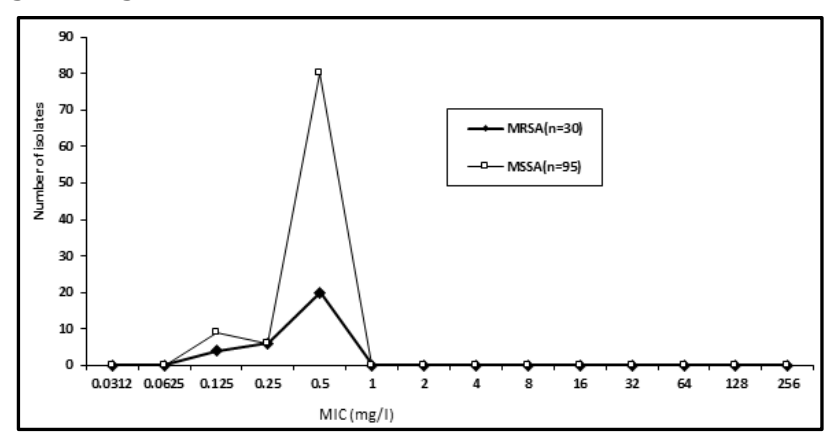

Figure 1 


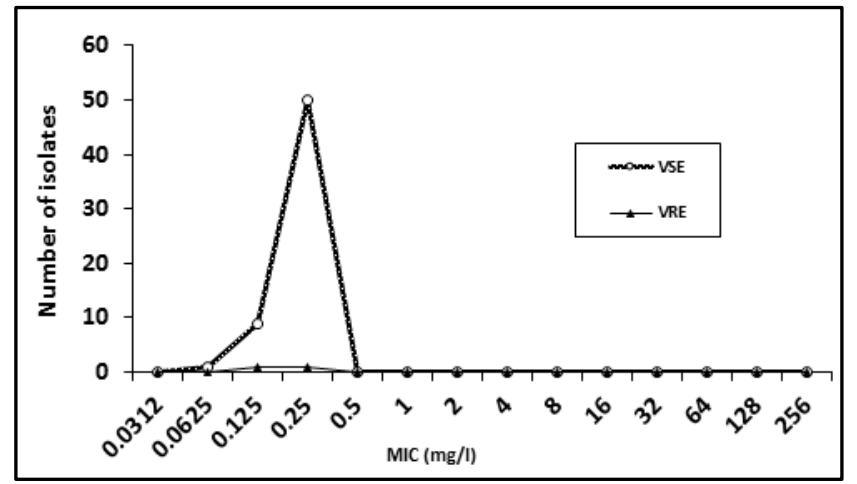

Figure 2

\begin{tabular}{|c|c|c|c|c|}
\hline \multirow{2}{*}{$\begin{array}{c}\text { Total Number } \\
\text { of Isolates }\end{array}$} & \multicolumn{4}{|c|}{ Number of Resistant Organism and MIC } \\
\cline { 2 - 5 } & $\mathbf{m g} / \mathbf{L}$ & $\begin{array}{c}\text { MIC } \\
\mathbf{1 6} \\
\mathbf{m g} / \mathbf{L}\end{array}$ & $\begin{array}{c}\text { MIC } \\
\mathbf{3 2} \\
\mathbf{m g} / \mathbf{L}\end{array}$ & $\begin{array}{c}\text { Total } \\
\text { Number of } \\
\text { Resistant } \\
\text { Isolates }\end{array}$ \\
\hline $\begin{array}{c}\text { A. anitratus } \\
\text { (n=54) }\end{array}$ & 8 & 6 & 2 & $16(29.6 \%)$ \\
\hline $\begin{array}{c}\text { P. aeruginosa } \\
\text { (n=3) }\end{array}$ & - & 1 & 1 & $2(66.6 \%)$ \\
\hline P. mirabilis (n=2) & 1 & 1 & - & $2(100 \%)$ \\
\hline $\begin{array}{c}\text { Enterobacter } \\
\text { spp. (n=13) }\end{array}$ & - & 2 & 1 & $3(23 \%)$ \\
\hline Esch. coli (n=30) & 1 & - & - & $1(3.3 \%)$ \\
\hline C. freundii (n=8) & 2 & - & - & $2(25 \%)$ \\
\hline \multicolumn{5}{|c|}{ Table 1. MIC of Resistant Gram Negative Bacilli } \\
\hline \multicolumn{5}{|c|}{}
\end{tabular}

\section{DISCUSSION}

The present study documented $24 \%$ of MRSA, 3\% VRE and $47 \%$ ESBL producers among the blood culture isolates. Tigecycline resistance was documented about $12.6 \%$ in case of ESBL producers, whereas MRSA and VRE isolates were sensitive to tigecycline. The emergence rate of MRSA isolates are similar to the two previous studies conducted in our centre, i.e. $26.14 \%$ by Kumari et al in 2003 and $26 \%$ by Baral et al in 2007 respectively. ${ }^{14,15}$ However, this finding does not corroborate the result of studies by Subedi et al in Western Nepal and Malik et al in India in which prevalence of $15.4 \%$ and $51.8 \%$ were reported. ${ }^{16,17}$ Among the VRE findings were similar to reports carried out previously in same institute in 2011, which showed 7\% vancomycin resistance (Sharma M unpublished - personal communication). However, in the year 2010 (Nepal H unpublished - personal communication), intermediate resistance was found. These results are in concordance to other studies conducted in India (1.5\%) and Tehran (7\%). ${ }^{18,19}$ Likewise, among 150 gram negative BSI isolates, $47.3 \%$ were found to be ESBL producers which was almost 2.5 times higher than the previous study conducted by Shrestha et al in same institution in year 2007 (18\%). ${ }^{20}$ The results regarding the prevalence of ESBL producers is similar to data derived from Pakistan - 45\% and India - 53\%.21,22 In our setting, however, status of ESBL is not regularly assessed and such 2.5 fold increment during the last 5 years interval highlights the need of the implementation of the regular surveillance of ESBL producers.

We studied the activity of tigecycline against 335 gram positive and gram negative isolates including MRSA, VRE and ESBL producers. Among the S. aureus isolates both the MSSA and MRSA were inhibited at MIC $\leq 0.5 \mathrm{mg} / \mathrm{L}$, i.e. susceptibility to tigecycline according to the MIC breakpoint given by the FDA. ${ }^{9}$ The study has been conducted in our setup for the first time, so we could not compare the results with others in our area or country. However, it is comparable to the reports available from many other studies, particularly from India. Manoharan et al and Behera et al reported all the S. aureus in their studies were inhibited at MIC of $0.25 \mathrm{mg} / \mathrm{L}$ and $\leq 0.5$ $\mathrm{mg} / \mathrm{L}$, though only MRSA were tested. ${ }^{23,24}$ Concording results were seen in a report from Pakistan, which showed susceptibility of MRSA to tigecycline with MIC range from $0.047-0.32 \mathrm{mg} / \mathrm{L} .{ }^{25}$ Reports from Tehran and the USA also showed the MIC value for the S. aureus with MRSA isolates to be $0.5 \mathrm{mg} / \mathrm{L} .1,3$ Regarding enterococci, all isolates including VRE showed susceptibility to tigecycline with MIC value $\leq$ $0.25 \mathrm{mg} / \mathrm{L}$, results similar to the study conducted by Manoharan A and Behera B.23,24 It was also consistent with studies conducted in other parts of the world. Seputienè et al from Lithuania reported MIC value for both VSE and VRE was in range of $0.12-0.25 \mathrm{mg} / \mathrm{L}$ and Sader HS from USA also reported the MIC value for VSE and VRE to be $0.25 \mathrm{mg} / \mathrm{L}^{1,26}$ So it appears that susceptibility to tigecycline among gram positive isolates as detected in present study was almost similar in any part of the world and the drug seems to be effective against them.

Out of 150 gram negative isolates, $82.6 \%$ were susceptible to tigecycline with MIC $\leq 2 \mathrm{mg} / \mathrm{L}$ and $17.3 \%$ were resistant with MIC $\geq 8 \mathrm{mg} / \mathrm{L}$. Among these isolates ESBL producers showed $12.6 \%$ resistance, whereas $22.7 \%$ of the ESBL non-producers were found to be resistant to tigecycline. So, irrespective of being an ESBL producing organism, gram negative isolates were found to be resistant to tigecycline. Resistance was seen among 26 gram negative isolates. MIC of these resistant organisms was seen ranging from $8-32 \mathrm{mg} / \mathrm{L}$. So, among A. anitratus, P. aeruginosa, P. mirabilis, Enterobacter spp., Esch. coli and C. freundii, 29.6\%, 66.6\%, $100 \%, 23 \%, 3.3 \%$ and $25 \%$ were found to be resistant respectively. A report from India showed that all the isolates of Esch. Coli, K. pneumoniae and Enterobacter spp. were inhibited at MIC $1 \mathrm{mg} / \mathrm{L}$ along with the ESBL production. ${ }^{23}$ Study in New Delhi reported all the gram negative MDR isolates along with ESBL producers showing good susceptibility to tigecycline with an exception to Acinetobacter spp., among which 58\% resistance to tigecycline was noted. ${ }^{23}$ Tigecycline activity was tested in 26,474 BSI isolates from 6 continents. It was highly active against gram negative organisms such as Esch. coli, Enterobacter spp., K. pneumoniae (MIC $0.25 \mathrm{mg} / \mathrm{L}, 1 \mathrm{mg} / \mathrm{L}$ and $2 \mathrm{mg} / \mathrm{L}$ respectively), but showed limited inhibition to $\mathrm{P}$. aeruginosa (MIC $16 \mathrm{mg} / \mathrm{L}$ ) and Proteus spp. $(4-8 \mathrm{mg} / \mathrm{L}){ }^{1}$ Resistance of P. aeruginosa as detected in our study with MIC value up to $32 \mathrm{mg} / \mathrm{L}$ is higher, but the MIC values are similar regarding the P. mirabilis isolates which got inhibited at 8 $16 \mathrm{mg} / \mathrm{L}$.

However, MIC value was high for some of Enterobacteriaceae isolates in our study as compared to their study. Results of all these studies imply that activity of tigecycline towards certain gram negative bacilli is not as good as it is towards gram positive cocci. It was not very active against $P$. aeruginosa and P. mirabilis and some strains of A. anitratus had less susceptibility. Perhaps, it is an indication towards the development of impending resistance in other gram negative organisms if preventive measures are not instituted on time. Present study has made an attempt to look into the activity of tigecycline against the isolates of BSI. All the isolates of S. aureus including MRSA and enterococci including VRE displayed susceptibility to tigecycline. 
However, $17 \%$ of gram negative organisms showed resistance to this drug. It indicates an alarming scenario, particularly in the context of a drug to which local isolates are yet to be exposed. Nevertheless, considering its long half-life and large volume of distribution along with good susceptibility against majority of gram positive and gram negative bacteria as well as the multidrug resistant ones, it can be regarded as a promising drug which should be preferably held in reserve and used judiciously. 5,27

\section{REFERENCES}

1. Sader HS, Jones RN, Stilwell MG, et al. Tigecycline activity tested against 26,474 bloodstream infection isolates: a collection from six continents. Diag Microbial Infect Dis 2005;52(3):181-6.

2. Basetti M, Nicolini L, Repetto E, et al. Tigecycline use in serious nosocomial infection: a drug use evaluation. BMC Infect Dis 2010;10:287.

3. Khalili $\mathrm{H}$, Khavidaki SD, Khalegi S, et al. Evaluation of tigecycline activity against methicillin resistant staphylococcus aureus isolated from biological samples. Iran J Pharm Res 2010;9(1):61-5.

4. Bradford PA. Extended-Spectrum $\beta$-Lactamases in the $21^{\text {st }}$ century: characterization, epidemiology and detection of this important resistant threat. Clin Microbiol Rev 2001;14(4):933-51.

5. Noskin GA. Tigecycline: a new glycylcycline for treatment of serious infections. Clin Infect Dis 2005;41 (suppl5): S303-14.

6. Citron DM, Edelstein MA, Garcia LS, et al. Microorganisms encountered in the blood. $9^{\text {th }}$ ed. In: Baron EJ, Peterson LR, Finegold SM, (eds). Bailey \& scott's diagnostic micribiology. Missouri: Mosby-Year book, Inc 1994:193209.

7. Barrow GI, Feltham RKA. Cowan and steel's manual for identification of medical bacteria. $3^{\text {rd }}$ edn. Catalogue, cambridge university press 1993.

8. Clinical and Laboratory Standards Institute. Performance standards for antimicrobial disk susceptibility tests. Approved standard 9th edn. CLSI document M2-A9. Clinical and laboratory standards institute, 940 West Valley Road, Suite 1400, Wayne, Pennsylvania 190871898 USA, 2006.

9. Wyeth Pharmaceuticals. FDA. Philadelphia: Wyeth Pharmaceuticals 2008:p 3. Available from: http:// www.accessdata.fda.gov/drugsatfda_docs/label/2009/02 1821s016lbl.pdf

10. National Committee for Clinical Laboratory Standards. Performance standards for antimicrobial susceptibility testing. Thirteenth informational supplement. NCCLS document M100-S13. Wayne, PA, 2003.

11. Clinical and Laboratory Standards Institute. Performance standards for antimicrobial disk susceptibility tests. CLSI document M100-S15. Clinical an Laboratory Standards Institute, 940 West Valley Road, Suite 1400, Wayne, Pennsylvania 19087-1898 USA, 2005.
12. Acar JF, Goldstein FW. Disk susceptibility test. $4^{\text {th }}$ edn. In: Lorian V. Antibiotics in laboratory medicine. Marryland: Williams and Wilkins 1996:28-32.

13. Murray PR, Baran EJ, Pfaller MA, et al. Manual of clinical microbiology. $8^{\text {th }}$ edn. In: Jana H, Swenson, Janet A. Hinder and Lance $\mathrm{R}$ Peterson. Special Tests for detecting Antimicrobial resistance. Washington ASM 1995:1359-60.

14. Kumari N, Mohapatra TM, Singh YI. Prevalence of methicillin resistant staphylococcus aureus in a tertiary care hospital in eastern Nepal. JNMA J Nep Med Assoc 2008;47(170):53-6.

15. Baral R, Khanal B, Acharya A. Antimicrobial susceptibility pattern of clinical isolates of staphylococcus in eastern Nepal. Health Renaissance 2011;9(2):78-82.

16. Subedi S, Brahmadathan KN. Antimicrobial susceptibility pattern of clinical isolates of staphylococcus aureus in Nepal. Clin Microb Infect 2005;11(3):235-7.

17. Mallik SK, Basak S. Methicillin resistant staphylococcus aureus-too many hurdles to overcome: a study from central India. Trop Doct 2010;40(2):108-10.

18. De A, Bindlish A, Kumar S, et al. Vancomycin resistant enterococci in a tertiary care hospital in Mumbai. Ind J Med Microbiol 2009;27(4):375-6.

19. Fatholahzadeh B, Farhad BH, Mohammad E. Detection of vancomycin resistant enterococci isolated from urinary tract infections in Tehran, Iran. DARU 2006;14(3):141-5.

20. Shrestha S, Amatya R, Dutta R. Prevalence of extended spectrum beta lactamase (ESBL) production in gram negative isolates from pyogenic infection in tertiary care hospital of eastern Nepal. Nepal Med Coll J 2011;13(3):186-9.

21. Ali AM, Rafi S, Qureshi AH. Frequency of extended spectrum beta lactamases producing gram negative bacilli among clinical isolates at clinical laboratories of army medical college, Rawalpindi. J Ayub Med Coll Abott 2004;16(1):35-7.

22. Duttatroy B, Mehta S. Extended spectrum beta lactamase in clinical isolates of Klebsiella pneumoniae and escherichia coli. Ind J Pathol Microbiol 2005;48(1):45-8.

23. Manoharan A, Chatterjee S, Madha S, et al. Evaluation of tigecycline activity in clinical isolates among Indian medical centers. Ind J Pathol Microbiol 2010;53(4):734-7.

24. Behera B, Das A, Mathur P, et al. Tigecycline susceptibility report from an Indian tertiary care hospital. Ind J Med Res 2009;129(4):446-50.

25. Sattar A, Abbasi AH, Faqir F, et al. Antimicrobial activity of tigecycline against methicillin resistant staphylococcus aureus in a tertiary care setting. Pak Arm For Med J 2011;1.

26. Seputienè V, Povilonis J, Armalytė J, et al. Tigecycline-how powerful is it in the fight against antibiotic-resistant bacteria? Med (Kaunas) 2010;46(4):240-8.

27. Georgopapadakou NH. 39(th) interscience conference on antimicrobial agents and chemotherapy (ICAAC) San Francisco, USA, 26-29 September 1999. Drug Resist Updat 1999;2(5):335-40. 